\title{
The Impact of Using Technology-Based Communication on Quality of Work Relationships
}

\author{
Madara PRATT, Sarma CAKULA \\ Vidzeme University of Applied Sciences \\ Cēsu iela 4, Valmiera, LV - 4201, Latvija \\ madara.pratt@va.lv, sarma@va.lv
}

\begin{abstract}
The use of modern technologies have changed work setting and this change offers us many advantages and benefits. Technology-based communication allows to span time and distance among people. Technology development is moving at such speed that social human behavior science has not kept pace. There is enormous research on human behavior, but we lack new models for guiding managerial practices. The aim of this research is to investigate technologybased communication effect on quality of relationships within the company and the factors affecting it. It was discovered that an important factor is cultural background of the company employees - the communication style and expectations for high context and low context cultures are very different. It is clear that technology-based communication within a company is negatively affecting quality of work relationships - it means that new methods should be discovered to power up technology-based communication. IT professionals should include this knowledge in their work in order to improve communication systems.
\end{abstract}

Keywords: technology-based communication, work relationships, high-context and low-context culture, computer supported cooperative work

\section{Introduction}

The ways of communication have changed and, in turn, changed the work environment; many companies developed virtual teams with team members in different cities, countries and even continents. This has developed new and more complex challenges for leadership, because of issues arising from new communication formats (Ekeland et al., 2010). The question is how to have highly performing, motivated and satisfied employees within companies, where communication is fully or partly technology-based.

Traditional relationship between employer and employee obviously has changed, but there is not a clear understanding about its replacement. We lack new models capable of guiding managerial behavior in this new era of work. Steers, Wickham and Acitelli believe that it is time to redirect intellectual energies into discovering new models and research towards new models of work motivation and job performance (Steers et al., 
2014). Barrier emphasizes that companies can not continue to blindly accept and introduce components into information systems without studying the effectiveness, feasibility and efficiency of the individual components of their information systems; these systems have to be managed (Barrier, 2001).

Although behavioral and social scientists have done enormous research on human behavior, researchers and developers have rarely utilized them (Kraut, 2003). In 2004 "ACM conference on Computer Supported Cooperative Work" held in Chicago, the topic of how to incorporate group and organization theory in CSCW (Computer Supported Cooperative Work) was discussed (Barley et al., 2004). It is clear from discussions that CSCW community should adopt a stronger orientation to social science disciplines (Ghaoui, 2005).

In addition to that, with a greater attention to psychological literature about human behavior in groups and organizational context, data can be collected and analyzed in a way that salient and generalizable features of human behavior are identified (Finholt and Teasley, 1998). Human-computer interaction (HCI) is a discipline with a focus on implementation of interactive computing systems for human use in a social context and the design and evaluation of these systems (Ghaoui, 2005). HCI research should strive to increase our understanding of the technology and its effects, to discover what impact computers (or uses of computers) are having on people's productivity, job satisfaction, communication with other people, and the general quality of their lives (Helander, 2014). Deep understanding of interactions between technology and complex social, political, and motivational dynamics is required in order to have effective support for multiple users, groups, or organizations (Wallace et al., 2017).

The aim of this article is to investigate how technology based communication is affecting quality of relationships within the company and which are the factors affecting it. The conceptual model (Fig. 2), developed by the authors, shows that relationship between technology-based communication work setting and quality of relationship is moderated by culture and development of social relationships among employees. Communication via technology has a negative effect mainly because of misunderstandings and anonymity (Levi, 2014). Considering cultural differences and implementing suggestions for the development of social relationships, the quality of relationships can be improved.

\section{Theoretical Background}

\subsection{Technology-Based Communication}

Computer Supported Cooperative Work (CSCW) is a research area where the use of computing and communication technologies, which support group and organizational activity, is studied (Ghaoui, 2005). The studies of CSCW are carried at four levels individual, group and team, organization, and industry. In wider perspective, family, occupation, nation, or culture can be discussed within CSCW. One of main focuses is to understand of how these communication technologies affect human behavior.

Information technologies can be experienced at 3 levels, called POA - process, outcome and affect. Within POA three key issues are approached - what user does, what user attains and how user feels (Dillon, 2002). Within these three steps the aim is to understand user's moves and attention through the information system, observe what it 
means for user to feel accomplishment or closure, and to identify what the interaction means for the user (Dillon, 2002). Researchers and developers should integrate the knowledge of social sciences within these three steps.

Technology allows us to have coordinated work in companies where employees are geographically dispersed. In many cases employees can be located in different places, countries and even continents. Also, working hours can be different - full time, part time work schedule and different shifts. Many companies have created virtual teams. The main reasons for developing virtual teams are to improve task performance, increase range and speed of information, and overcome time and space distances (McGrath and Hollingshead, 1994). Other benefits of virtual teams are discussions based on knowledge, facts and improved brainstorming (Levi, 2017).

These teams rely heavily on virtual communication, including phone calls, e-mails, instant messaging, video chats, videoconferences, shared screen sessions, shared files and others. The degree of virtual communication within organization or teams can be discussed at three levels - face-to-face teams that meet personally, low virtuality teams that use synchronous, media-rich technologies and high virtuality teams that use asynchronous, media poor technologies, such as e-mail (Mesmer-Magnus et al., 2011). Criteria for technology can be analyzed in terms of speed, interactivity, richness and documentation of messages (Levi, 2014).

Companies can categorize their meetings in four categories by time and place (Mittleman and Briggs, 1999). STSP (same-time, same-place) are face-to-face meetings. STDP (same-time, different-place) meetings are combination of video, audio or text. The information technology serves as a storage system. DTSP (different-time, same-place) meetings work as a storage system and are used for example for employees with different shifts. Within DTDP (different-time, different-place) meetings team members share the same virtual space and web (Levi, 2014).

Companies have to be cautious of effects that technology has on their work environment and relationships. Technology has an impact on work design, organizational design, communication patterns and secondary social effects (Hartman et al., 1991). Without clear understanding and strategy, technology can cause several issues. The challenges of these kinds of teams are miscommunication, less social rapport, more task orientation, lack of interpersonal relationships and lower member satisfaction (Levi, 2017). In order to overcome these challenges Levi suggests having face-to-face communication in initial phase of employment (Levi, 2017).

Communication technologies change how status is perceived; communication within this context is based on knowledge and opinions. It decreases status differences. In faceto-face meetings there are one or few persons who talk; controversial virtual communication tends to be more democratic (Levi, 2014).

Other effects are increased anonymity and increased amount of miscommunication. Taking into consideration that within technology-based communication part of the intended message can be lost and the absence of non-verbal cues, it can lead to miscommunication, lack of personal relations, social rapport and less satisfied members (Levi, 2017), the amount of this communication within company can be a significant measurement of quality of relationships among these team members. Within this paper, author predicts, that the more communication is through computer-based technologies, the lower is quality of relationships within company.

Although technology offers many benefits, human interaction promises much more. However, the work environment has changed and these issues have to be solved and 
research of social sciences integrated in company and developer strategies, in order to have more satisfied employees and gain competitive advantage in the market.

\subsection{Richness of Communication}

Communication is a very critical part of our lives - private life as well as business life. We develop our communication skills beginning in early childhood and these include expressing our thoughts in an understandable manner and exchanging ideas with other people around us. The means of communication are not only through our words and our language but also through our body language, our tone of voice and our emotions. Most of human communication is non-verbal; it can be through kinesics (facial expressions, gestures, body movement etc.), proxemics (perception and use of space) and chronemics (perception and use of time) dimensions.

\subsection{Development of Social Relationships}

Two main challenges that companies have to overcome are communication problems and creation of effective interpersonal relationships (Thompson and Coovert, 2006).

One of the impacts of technology-based communication is increased anonymity. There are several effects. First of all, it results in loss of self-awareness. Deindivualization can result in social loafing. People would say what otherwise they would not say in face-to-face communication. Within this communication there is less pressure and it affects how teams make decisions and resolve conflicts. Having less social pressure can result in higher levels of conflicts, inability to resolve conflicts and to reach consensus in decision-making situations (Levi, 2014). There are also benefits of anonymity - better generation of ideas, greater willingness to participate and to generate more ideas (Levi, 2014). Another issue is miscommunication, because of misunderstandings and reduced communication, that results in conflicts (Hertel et al., 2005).

It was thought that increased levels of videoconferencing would solve these communication problems; however, expectations were not realized (Thompson and Coovert, 2006). Videoconferencing does not require full attention as face-to-face communication and mainly matched the name to face, but doesn't substitute for face-toface communication, because of its inability to read non-verbal cues (Hambley et al., 2007).

Most of the work is done individually; within this work setting, well-defined structure and consistent meetings are necessary. For building social relations it is suggested to have face-to face meetings including social activities and to encourage employees to communicate informally on every day basis; it is normal practice to use technology for bonding social ties among employees (Levi, 2014).

Vignovic and Thompson suggest concentrating on developing social relations and using communication norms in order to overcome communication problems (Vignovic and Thompson, 2010). Both low and high virtual teams can take advantage of communication norms. Some of the suggestions for having norms are:

For e-mails: construction, timeline of responses and recipients of e-mail messages; not sending an e-mail when upset or in an emotional state; 
For videoconference: start the conference with letting know who is present, no side conversations, notification if something is unclear (Levi, 2014).

\subsection{High-context and Low-context Cultures}

Even though all people learn to communicate at an early age, we have differences in the way we convey and perceive information. These differences can evolve from our personalities, education, experience, and intelligence and also are deeply rooted in our culture. As Hall noted in his book "The Silent Language" - "Culture is communication and communication is culture" (Hall, 1976).

We think, behave, assign value, and interact with each other in different ways and with that in mind, culture becomes a focal point in research of technology-based communication (Ghaoui, 2005).

Cultural differences have to be considered, work communication cannot use static and inelastic model for every situation. Impact of communication differs depending on culture and age differences (Tannenbaum, 2012). Cultural background is an important factor influencing abilities and qualities of technology user for system developers to consider. Röse and Züblke recognized a gap in developer's knowledge when handling product design according to the culture dependent user requirements of a foreign market (Röse and Züblke, 2001). Within the research about specification, analysis and integration of relevant intercultural variables, Röse specified, that modern and userfriendly products have to include cultural diversity as one of their key features (Röse, 2004).

Culture is a very complex concept and can be discussed from many different perspectives. Within this article, communication is the main concern. The richness of communication varies among different cultures. Hall developed a theory of low-context (LC) and high-context (HC) cultures (Hall, 1976). This theory has helped to understand the world and, by showing differences, help distant cultures find ways of understanding each other better. The most important premise is to understand that each culture has a different way of communicating deeply rooted in their biological past, history, traditions and societal norms. The more distant the cultures, the more complex the communication becomes and mutual understanding is harder to achieve. In many cases, understanding of another party has been disrupted because of these reasons. Knowing the culture of an opposite party can ease communication and have great benefits, because the way of thinking is strongly affected by culture.

One might think that communication problems stem from differences in linguistic codes, but Hall argues, that the problem lies in the context, which carries varying proportions of the meaning (Hall, 1976). Spoken language in fact is an abstraction of thoughts and, in turn, written language is an abstraction of spoken language. The actual event happening is much more complex and richer than the abstraction of it within spoken language and written language. It is natural that people choose some parts of information and unconsciously ignore others.

According to Hall, the patterns of perceiving information are learned early in life and taken for granted (Hall, 1976). What man perceives is influenced by five sets of different categories of events - the subject or activity, the situation, one's status in a social system, past experience, and culture. There are many factors to be considered in order to convey a message in multicultural context. Also any transaction can be characterized as high, low or middle context (Hall, 1976). Hall has presented a model in his book 
"Beyond Culture" (Fig. 1) which shows the difference between HC and LC culture communications (Hall, 1976). There is much more context and little or no information in HC communications, but LC communication provides a lot of information with little or no hidden context.

High-context culture communication context is rooted in the past; communication meaning is deeply embedded in information and not everything is explicitly stated in written or spoken language. It is indirect and within this communication there is a tendency to talk around things. This communication involves emotions and close relationships, disagreements are personalized. Within this communication trust is built slowly and personal identity tends to be based in groups, such as family or work groups (Bennett, 1998).

Low-context communication is based on the logical part of the brain and is less personal (Bennett, 1998). There is more direct meaning explicitly stated through language.

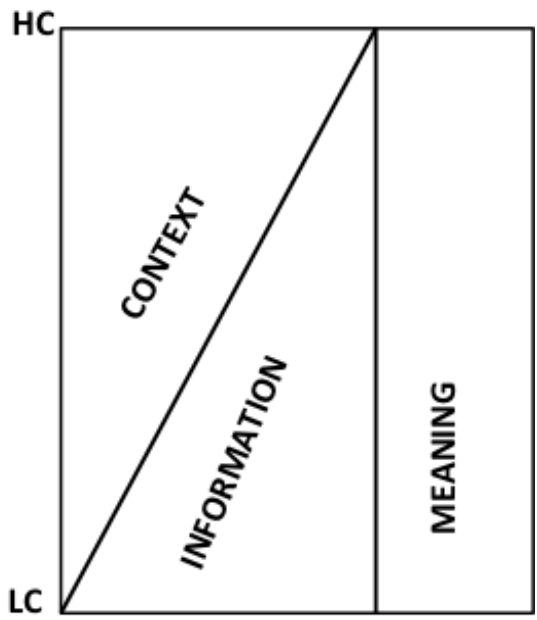

Fig. 1. Information and meaning in HC and LC communication (Hall, 1976).

Communication within this culture is direct, precise, dramatic, open, and based on feelings or true intentions (Gudykunst et al., 1988). There is more emphasis on task, roles and what needs to be done. Disagreements focus on rational solutions and problem solving is based more on data analysis. In LC communication, personal identity tends to focus on one's accomplishments.

The most HC cultures are Japan, Arab countries, Southern Europe and the most LC cultures are German-Speaking countries, Scandinavian Countries and North America (Hall, 1976).

$\mathrm{HC}$ and LC communication can differ by emotional expressions and relationship building, directness of message conveyed, use of verbal or nonverbal behaviors, and use of digital or an analogous language (Salleh, 2005). Within technical development and modernization, very large part of people communication has shifted to digital 
communication, which is more direct. These technologies help us save time and disregard the distance. At the same time, however the communication is losing its critical part of context that is carried in a message. Generally, technology carries lowcontext messages and deeply embedded in information which can be unseen and missed. In a changing and complex world, low-context communication is saving time and information overload, but at the same time it can be losing meaning.

Within technology-based communication, the most complex issue is transmitting desired message in high-context cultures. As most of the meaning is not transmitted in words, it can lead to misunderstandings. In general HC communication is economical, fast, efficient and satisfying. To have sufficient $\mathrm{HC}$ communication programming has to be done; if that is not done, this communication is insufficient (Hall, 1976). Controversy in LC communication can be very brief and short and not have all information explained in sufficient detail and lack emotion and personal relationships. In work context, quality of work relationships is as important as practical outcomes. Organizations with technology-based communication have to consider this cultural aspect in order to assure better quality of relationships within their company. Thompson and Coovert's experiments revealed that within e-mail communication, receivers formed negative perception if e-mail contained technical language violations, but these negative perceptions were reduced when they had information that the sender is from a different culture (Thompson and Coovert, 2006). Negative attributions from etiquette violations were not reduced even if it was known, that it was received from a source in a foreign country (Thompson and Coovert, 2006). This proves the importance of cultural research within companies using technology based communication channels. Within use of these suggestions technology based communication can have less negative effect on quality of relationships within a company.

\subsection{Quality of Relationships}

There is no doubt that technology-based communication is affecting the quality of relationships in the company. Communication is an important factor for maintaining social relations and organizational culture and lack of social information can limit social relations in the company (Duarte and Snyder, 2006).

It is difficult to establish and maintain mutual knowledge (Driskell et al. 2003). When the facial expressions and non-verbal cues are missing, it is harder to understand if information was understood. For example, in an e-mail it is not always clear if a person is being sarcastic or funny and experiments have proven that people think they can communicate more efficiently than they actually can. These studies suggested that the overconfidence comes from egocentrism, the inherent difficulty of detaching oneself from one's own perspective when evaluating the perspective of someone else (Kruger et al., 2005). These misunderstandings can lead to false conclusions and assumptions about person's character especially when communication is across cultures (Levi, 2017; Vignovic and Thompson, 2010). 


\subsection{Conceptual model}

Technology-based communication is critical because of its influence on several factors and the connections between the variables can be arranged in a conceptual model (Fig. 2) reflecting major constructs from literature review.

From presented literature review it can be concluded that technology based communication (the amount of technology used) is affecting quality of work relationships, which is mediated by culture and can be influenced by face-to-face events and norms. The more work communication is done through technology-based means, the harder it is to maintain high quality relationships inside the company.

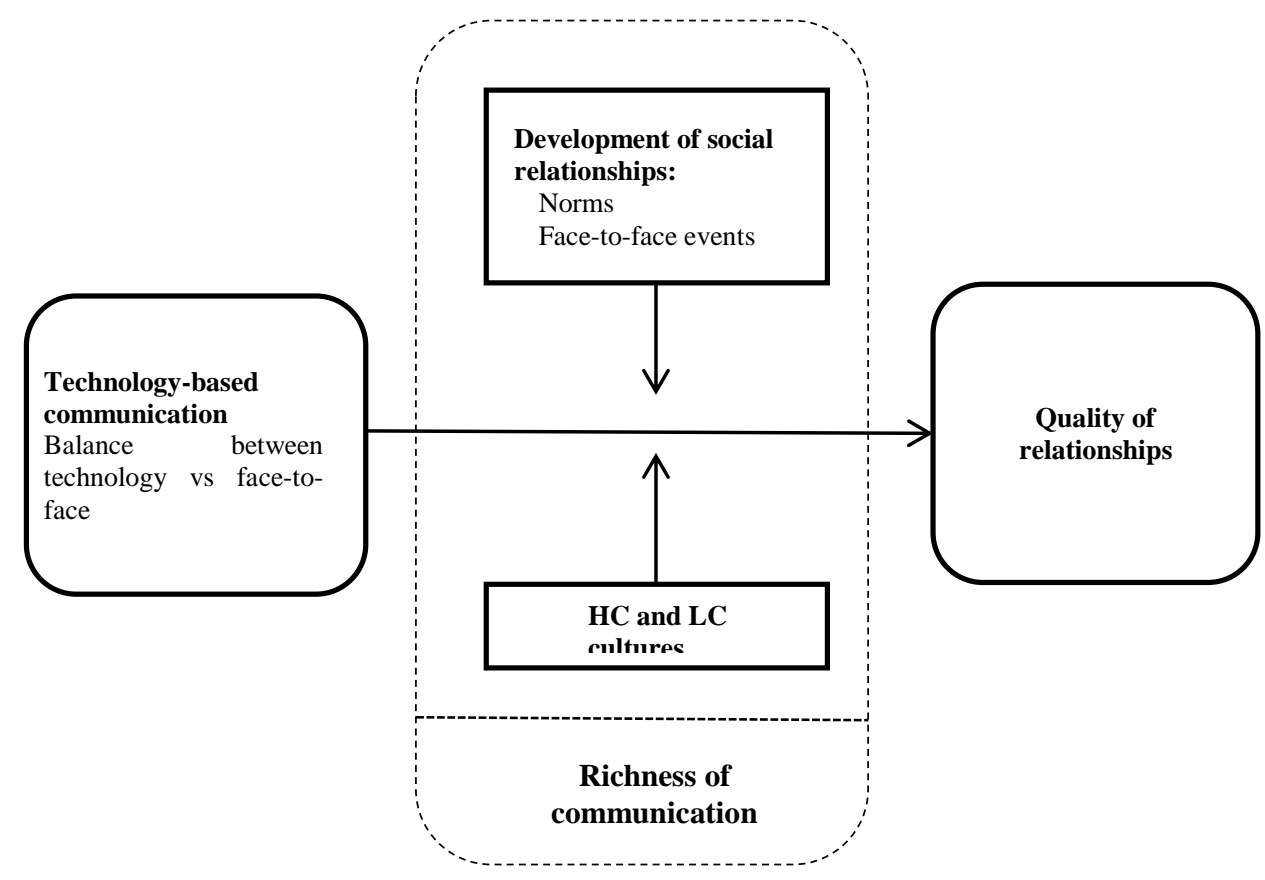

Fig. 2. Conceptual model of technology-based work communication (created by the authors)

\section{Conclusion and Future Work}

In this article, the lack of concentration on human behavior science in CSCW work is recognized. The future competitive advantage will be motivated work force in combination with advanced technologies. CSCW community should adapt stronger orientation to social science disciplines (Finholt and Teasley, 1998). The effects and impacts of computers and their use on employees' job satisfaction and communication 
have to be understood. There is a call for research and new contextual models capable of guiding managerial work behavior in the new era of work (Steers et al., 2014). The work context has changed dramatically. The old model of communication has changed and there is a little understanding of the new model that has taken place.

The current article has described relevant literature pointing out the most important theories and influencing aspects of presented contextual model. The model (Fig. 2) presents relationships between technology-based communication work setting and quality of relationships among employees. The connection of these variables is clear and the more communication in the company is through technology-based means, the less is the quality of relationships among members. There are several suggestions for improving these relationships.

First of all the cultural differences have to be taken into account, especially in a multicultural context. LC culture members tend to be more specific and clear with their messages, while HC culture members tend to have hidden context and messages that are not so clear, because of missing context that is rooted in the past. It is known that one of the main struggles in technology-based communication is miscommunication and it is a very important concept to consider in multicultural organization (Levi, 2017). The cultural aspect is a moderator in relationship between the amount of technology-based communication and quality of relationships within a company. The better is the understanding of the culture or cultures within a company, the more possible it is to design and program communication in a way that it improves the relationships among members of the company.

Another mediator that can improve quality of relationships is development of social relationships. There are several suggestions on how to do it. First of all, the most important is to have face-to-face meetings in initial phase of employment. Also it is suggested to have periodic face-to-face meetings afterwards. Company meetings and training programs are beneficial for developing better social relationships among members of the company. Employee-employee relationships are also important. These peer relationships create bonds and trust in the team and company. Possibly pairing new employees with experienced employees could be used to support and help create loyalty and trust. Another suggestion is to encourage employees to socialize with co-workers through technology. Second way of ensuring better social relations is to introduce norms using technology to avoid misunderstandings; for example, creating the rules of writing e-mails or attending videoconferences.

For further research authors recognize the importance of leadership as the most important role in maintaining good quality of relationships within the company. Leaders have more challenges within virtual teams than those who work mostly face-to-face. These companies have to develop according strategies taking into account all mentioned influencing aspects.

In future research this model should be continued by investigation on technolgybased communications effect on work motivation and work satisfaction. Quality of work relationships are expected to have an influence on employee satisfaction and this idea could be discussed in order to extend the current model. 


\section{References}

Barley, S. R., Dutton, W. H., Kiesler, S., Resnick, P., Kraut, R. E., Yates, J. (2004). Does CSCW need organization theory? In Proceedings of the 2004 ACM conference on Computer supported cooperative work, pp. 122-124.

Barrier, T. (Ed.). (2001). Human computer interaction development \& management. IGI Global.

Bennett, M. J. (1998). Basic concepts of intercultural communication: Selected readings. Intercultural Press, Inc., PO Box 700, Yarmouth, ME 04096.

Dillon, A. (2002). Beyond usability: process, outcome and affect in human-computer interactions. Canadian Journal of Library and Information Science.

Driskell, J. E., Radtke, P. H., Salas, E. (2003). Virtual teams: Effects of technological mediation on team performance. Group Dynamics: Theory, Research, and Practice, vol. 7, no. 4, pp. 297 323.

Duarte, D. L., Snyder, N. T. (2006). Mastering virtual teams: Strategies, tools, and techniques that succeed. John Wiley \& Sons.

Finholt, T. A., Teasley, S. D. (1998). Psychology: The need for psychology in research on computer-supported cooperative work. Social Science Computer Review, vol. 16, no. 1, pp. 40-52.

Ghaoui, C. (Ed.), (2005). Encyclopedia of human computer interaction. IGI Global.

Gudykunst, W. B., Ting-Toomey, S., Chua, E. (1988). Culture and interpersonal communication. Sage Publications, Inc.

Hall, E. T. (1976). Beyond Culture. New York.

Hambley, L. A., O'Neill, T. A., Kline, T. J. (2007). Virtual team leadership: The effects of leadership style and communication medium on team interaction styles and outcomes. Organizational behavior and human decision processes, vol. 103, no. 1, pp. 1-20.

Hartman, K., Neuwirth, C. M., Kiesler, S., Sproull, L., Cochran, C., Palmquist, M., Zubrow, D. (1991). Patterns of social interaction and learning to write: Some effects of network technologies. Written Communication, vol. 8, no. 1, pp. 79-113.

Helander, M. G. (Ed.). (2014). Handbook of human-computer interaction. Elsevier.

Hertel, G., Geister, S., Konradt, U. (2005). Managing virtual teams: A review of current empirical research. Human resource management review, vol. 15, no. 1, pp. 69-95.

Huang, R., Kahai, S., Jestice, R. (2010). The contingent effects of leadership on team collaboration in virtual teams. Computers in Human Behavior, vol. 26, no. 5, pp.1098-11.

J. McGrath, and Hollingshead, A. (1994). Groups interacting with technology. Thousand Oaks, CA: Sage.

Kraut, R. E. (2003). Applying social psychological theory to the problems of group work. HCI models, theories and frameworks: Toward a multidisciplinary science, pp. 325-356.

Kruger, J., Epley, N., Parker, Ng, J., Z. W. (2005). Egocentrism over e-mail: Can we communicate as well as we think? Journal of personality and social psychology, vol. 89, no. 6, p. 925.

Levi, D. (2014). Group Dynamics for Teams. 4th edition, Sage Publications, Inc.

Levi, D. (2017). Group Dynamics for Teams. 5th edition, Sage Publications, Inc.

Mesmer-Magnus, J. R., DeChurch, L. A., Jimenez-Rodriguez, M., Wildman, J., Shuffler, M. (2011). A meta-analytic investigation of virtuality and information sharing in teams. Organizational Behavior and Human Decision Processes, vol. 115, no. 2, pp. 214-225.

Mittleman, D., Briggs, R. (1999). Communication technologies for traditional and virtual teams. Supporting work team effectiveness, San Francisco, CA: Jossey-Bass, pp. 246-270.

Röse, K. (2004). The development of culture-oriented human machine systems: specification, analysis and integration of relevant intercultural variables. In Cultural ergonomics Emerald Group Publishing Limited, pp. 61-103.

Röse, K., Züblke, D. (2001). Culture-oriented design: Developers' knowledge gaps in this area. IFAC Proceedings Volumes, vol. 34, no. 16, pp. 11-16. 
Salleh, L. M. (2005). High/low context communication: The Malaysian Malay style. In Proceedings of the 2005 Association for Business Communication Annual Convention, Irvine, CA: Association for Business Communication, pp. 1-11.

Steers, M. L. N., Wickham, R. E., Acitelli, L. K. (2014). Seeing everyone else's highlight reels: How Facebook usage is linked to depressive symptoms. Journal of Social and Clinical Psychology, vol. 33, no. 8, pp.701-731.

Tannenbaum, S. I., Mathieu, J. E., Salas, E., Cohen, D. (2012). Teams are changing: Are research and practice evolving fast enough? Industrial and Organizational Psychology, vol. 5, no. 1, $2-24$.

Thompson, L. F., Coovert, M. D. (2006). Understanding and developing virtual computersupported cooperative work teams. Creating high-tech teams: Practical guidance on work performance and technology, Washington, DC: American Psychological Association.

Vignovic, J. A., Thompson, L. F. (2010). Computer-mediated cross-cultural collaboration: Attributing communication errors to the person versus the situation. Journal of Applied Psychology, vol. 95, no. 2.

Wallace, J. R., Oji, S., Anslow C., (2017). Technologies, methods, and values: Changes in empirical research at CSCW 1990-2015. Proceedings of the ACM on Human-Computer Interaction, 1(CSCW), 106.

Received February 18, 2020, accepted March 14, 2020 